\title{
Examining Working Methods on Reducing Expenses in Islamic Azad Universities: Perspective of Faculty Members of Isfahan (Khorasgan) Branch
}

\author{
Maedeh Soheili Isfahani \\ Department of Humanities Sciences, Isfahan (Khorasgan) Branch, Islamic Azad University, Isfahan, Iran \\ Email: maedehsoheili@yahoo.com \\ Mohammad Alimoradi \\ Department of Humanities Sciences, Isfahan (Khorasgan) Branch, Islamic Azad University, Isfahan, Iran \\ Email: alimoradi@khuisf.ac.ir
}

\section{Doi:10.5901/mjss.2015.v6n3s1p445}

\section{Abstract}

\begin{abstract}
Islamic Azad universities are autonomous and non-profit institutions where almost all the expenses are provided through students' tuitions. In recent years in accordance with extreme quantitative development of institutions of higher education, reduction in the number of university student candidates, paltry increase in tuitions, and considerable increase in construction and current expenses, management of expenses in Azad universities has turned into a vital concern. The present study aims to examine working methods for decreasing the expenses of the universities, investigating the effect of five factors including targeting activities, organizing manpower, mechanizing systems, controlling, observing, and downsizing the university, on reducing expenses in Islamic Azad Universities. The study is conducted in descriptive survey method and the population of the study was all 320 faculty members of Islamic Azad university of Isfahan (Khorasgan) in March, 2014. 175 people were chosen by Morgan Table through available random sampling as the sample of the study. The instruments were questionnaires designed by the researcher and the data was analyzed through Uni-variate $t$ Test, Friedman Test, and Analysis Variance through spss-19 software. The result revealed that all five factors in the study have significant effects on reducing expenses in the universities and manpower had the highest effect whereas, controlling and observing had the least effect.
\end{abstract}

Keywords: Targeting activities, Organizing manpower, Mechanizing systems, Controlling, Observing, and Downsizing the university.

\section{Introduction}

Islamic Azad University is a non-profit institution and it was established in 1982 to fulfill the objectives mentioned in regulations for the establishment of non-profit institutes of higher educations. The budget is obtained mainly from tuitions, sometimes private contributions, research activities, and the like and it is spent for improvement and development of research and education as well as creating and supporting facilities for research and education. In the last two decades, the quantitative development of institutions of higher education and decreasing the population growth rate, have resulted in the reduction of student candidates to universities. Moreover, some institutions of higher education including some branches of Islamic Azad universities have vacant chairs.

Some branches of Islamic Azad universities which merely rely on tuitions from students to supply their financial resources have faced with serious problems because of the mentioned issues as well as inflation in recent years. New financial resource and reducing expenses are two general issues to overcome these situations. To do so, investigating working methods on increasing financial resources and reducing expenses in Islamic Azad universities is essential. This perspective is of highest importance even in Branches in which financial issues have not been demanding yet and could be beneficial in having a promising future. This study aims to examine the working methods on reducing expenses via the perspective of the staff in Isfahan. Therefore, the main question here is that what are the working methods on reducing expenses through the perspectives of faculty members in Isfahan (Khorasgan) Branch?

\section{Theoretical Framework of the Study}

Studies on organizations of Economic and Development Cooperation (2007) on some of the country members have shown that financial resources system of higher education has significant effect on higher education development and 
consequently influences on social and economic development in countries. It should be considered that any financial resource system for higher education does not fit to the development of higher education industry as well as economic development. Some systems of supplying financial resources motivate development but some inhabit it; therefore, today countries are trying to recreate financial resources system of higher education in such a way that fulfills the objectives of development in the best ways (Johnstone and Marcucci, 2010). The theoretical analysis and experimental evidence of higher education issues show that the existing system of supplying and allocating finance for higher education in Iran is not consistent with the development objectives. In this respect, four main issues are as follows :1) people`s availability to the "qualitative learning opportunities", 2) equal availability to higher education and equal distribution of incomes and opportunities, 3) lack of attention to the efficiency in higher education (the efficiency in higher education is on individual, organization, and macroeconomic levels), and 4) lack of sufficient attention to production and distribution of primary science ( like public goods) (Entezari, 1391).

\section{Literature Review}

Considering Islamic Azad Universities as newly-established organizations, issues like extreme development of higher education institutes, reduction in number of university student candidates, and considerable increase in construction and current expenses have made universities be in dire straits and unfortunately no direct research studies on the working methods and efficient factors has been done yet for reducing expenses on these universities.

In this respect, the present study is novel, therefore, considering lack of similar and direct studies on this area of interest the literature on research studies which have similar subject to this study include: Safari (2004), in the study by the title of "Important and efficient factors on increasing financial resources, university students attraction, and reduction of expenses in Islamic Azad Universities through managers ' perspective" concluded that the most important factor in reduction of expenses in Islamic Azad Universities is the reduction of inflation rate by the government. Faraj Pahlou and Maki Zadeh (2010), in investigation of expense- usefulness of data bases of Yazd University in 2009 concluded that the high increase of expenses for using data banks in all over the world, have made many organizations contemplate about it and analyze this issue from financial and economic aspects. In this respect, considering the finished expenses is vital issue to prevent wasting resources, and logical expenses reduction and using facilities are taken in to account as well. Naveh Ebrahim (2002), studied budget deficit and the cost of wastage in state higher education through a case study in an expert university of base science and calculated the amount of wastage expenses because of the number of failed students and repeating the courses among university students in BA program during 1370-1380 decades and examined the rule and its relation to the university budget.

Findings proved that wastage expenses recovery in educational programs could have important effect on supplying budget deficit in these universities. This study has shown that a considerable amount of financial resources of public section is used on wastage expenses in educational programs and wastage expenses have efficient role on creating budget deficit in state universities.

Horn and Hoo (2008) estimated the efficiency of expenses in 36 universities during 1995 to 2002 through Stochastic Frontier Analysis. This study was different from prior studies in universities in Australia through two aspects. First, applying Stochastic Frontier Analysis method and second, providing the data panel for estimation which enables expense function to compare expense productivity across universities as well as providing a econometrics test from the assumption of function of similar expenses for each university. The main finding was that universities at that time of investigation are not efficient as a relative function of expense productivity. Bit et al. (2003), assuming that the main objective of universities is conducting primary research studies by gaining public budget, assigned the objective of their study as model development of connection between universities and industry and using it for designating optimum tax on research incomes in universities. The primary Model for this instrument was Compton Tax in MIT in 1930s. Based on the research studies, interviewing with experts, and experiences and recognitions of researchers form Azad universities, the following five factors are known as working methods for reducing expenses in universities.

\subsection{To make the university's activities targeted}

Making the university's activities targeted is a working method by which the favorable objectives with defined resources will be fulfilled and expenses will be reduced. The efficiency of universities will be improved and the quality of different sub-sections and groups will be assured to prevent wastage of man power and investments and to increase competitive power especially through international levels ( Hossein pour, 1390). Base on limitations on financial resources of universities, the precise prioritizing of plans and programs and how to allocate financial recourses to them is the main 
issue in making the university's activities targeted. As research studies show (Odden \& Clune, 1998; Unsco/Oecd, 2002; Vegas, 2002; Odden, 2004) in most countries, reform or change to financial recourse allocation system is known as an important instrument in management of higher education system and research and educational policy making. Therefore, to improve higher education performance, applying appropriate mechanism of financial resources allocation as an efficient and useful solution has been welcomed. In this study, making the university's activities targeted is meant prioritizing plans and programs in universities, deleting duplications and activities without added value, organizing physical facilities by organizing building and development, educational, cultural and research activities, deleting unpopular majors, limiting congresses and plans within universities with increasing productivities approach, limiting or even stopping physical development of universities and things like that.

\subsection{Organizing man power}

From the important factors about attracting and protecting man power we can count on different environmental factors such as: economical factors, social factors, technological and reputational factors; moreover, organizational factors include: rewarding employees and management of employee improvement. Rewarding is defined as external and internal rewards towards employees' services in organizations which are paid fairly. Rewarding is not merely through salary or wage increase but it could be non-cash payments like treatment service insurance, pension, social and computational interactions in workplaces like observations from supervisors, occupations positions, and occupations challenges and promotions( Dollan \& shouller, 1997).

Considering employees' success circle and grouping them for man power planning are of highest importance; since spending huge expenses for in-service and after service. Training and system slow down due to new crew to the organization increase the total expenses (Sa adat, 1998). By organizing man power in this study it is meant, quantitative and qualitative organizing including correct and appropriate man power transfer across universities branches, balancing man power through before-appointed time retirement planning, holding practical in-service training courses for employees and faculty members, specialists orientation in assigned affairs and developing welfare facilities for the employees by the aim of increasing efficiency and satisfaction.

\subsection{Mechanizing office, financial, training, and research systems}

Using well-known and advanced software system planning allows the organizations go ahead through success and promote along with other organizations and markets. Considering computer programs in most goods and services markets, any organizations which lack these systems not only cannot compete but also are behind the schedules and cannot achieve their goals. Equipping the organizations with advanced technologies including new technology of production and services and applying advanced software as well as teaching and training the employees for fast, in time, and correct use of these technologies, mechanizing systems by valid software and ignoring trial and error prevent repetition and extra expenses and waste of resources. Although one of the objectives of entering computers to the organizations is downsizing and economizing in office and personals expenses, there are no changes in reducing the man power in most organizations in Iran and, and on the contrary the man power increases due to lack of familiarity with optimal use of technology and resistance to change. Therefore, in most cases the man power increases and that means the technology has not known yet (Safari, 2004).

Karami (2011), in a study by the title of the position of electronic customs in facilitating commercial affairs concluded that electronic trading and careers facilitates trading affairs so that completing trading processes for export and import in less time and costs is possible.

By mechanizing office, financial, training, and research systems in this study is to install and position comprehensive and mechanized systems in all levels of universities branches and to avoid island software to reduce bureaucracy and to facilitate office works, training, and research affairs.

\subsection{Observation and controlling}

Observation and controlling are of the main components of management in any organizations so that by ignoring one of them the other components of management like planning, organizing, leadership, and direction are imperfect. In fact, after planning, organizing, and leadership and direction methods it is expected that the objectives be realized and the performance procedures be fulfilled. Sometimes even the details of the plan are done precisely but the main direction of which is deviated and is away from the targets. To ensure about the performance and the direction of the plan and 
preventing and deviation from the main objectives essential actions are needed which are observation and planning (Safari, 2004). Interior auditing, an investigation system, is for evaluating interior activities of the organization in order to detect the deviation rate form designated standards in the organization. The information from this system should be in a way that informs the management about organizations current actions, observing state rules, having a good financial position, profit making of actions, and coordination among different parts of the organization (Zahedani, 1999). On the other hand, interior controlling includes all individuals, units, and actions by which all methods, activities, options, and responsibilities are investigated. Therefore, interior controlling is not limited to the financial issues. After interior controlling, the most important action is detecting deviations by examining strategic points, analyzing their reasons, and taking immediate reforming actions for getting to standard levels and approved classifications. Erabi et al. ( 2011), in a study by the title of "Another engineering of importing procedures, investigated importing procedures in Iran Customs Office and concluded that Iran Customs needs another engineering and it would be a response to changing environmental needs. Asad nia et al. (2013), in a study by the title of the effect of operational auditing on efficient performances of development plans of the police concluded that operational auditing influence the efficiency of the development plans of the police. By controlling and observation in this study we mean, creating modern methods of management of expenses, more emphasis on budgeting, creating supplying credit and budget controlling systems, positioning interior auditing, reforming and improving purchasing procedures, other needed services for universities in different levels of transactions, and evaluating the results from using financial resources of universities and so on.

\subsection{Downsizing the university}

The size of an organization is one the main points in increasing the expenses. Proportion to the size of the organization, there are manpower, equipment and facilities. The bigger an organization, the more need to the man power, equipment, and buildings; consequently more increase in expenses. Rational downsizing is one of the important factors in reducing expenses provided that production and services would not harm. Deleting or integrating false or unnecessary occupations is one of the steps for the downsizing. Dismissing unwanted man power would reduce the personals and office expenses therefore; the organization could utilize other investments in other parts or even out of the organization (Nabavi, 1997). In this study, downsizing means deleting or integrating unnecessary occupations and integrating different centers or small units into a big and comprehensive one. Based on mentioned factors the conceptual model of the study is shown in figure 1.

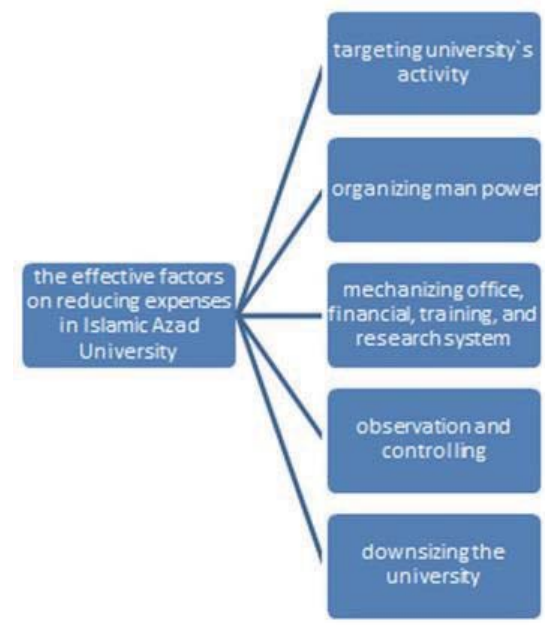

Figure 1: The Conceptual Model of the Study

In this study, the researchers aim to examine, test, and rank the effect of these five factors on reducing expenses in Islamic Azad Universities, Isfahan Branch (khorasgan) by faculty members' perspective.

\section{Method}

Based on the research objective, that is examining working methods of reducing expenses of Islamic Azad University , through faculty members' perspective of Isfahan ( khorasgan), branch the method is descriptive survey. The population of 
the study were 320 faculty members of Islamic Azad university of Isfahan(Khorasgan) in March, 2014. Based on the number of the population, 175 people were chosen by Morgan (1970) Table through available random sampling as the sample of the study. For the data collection the researcher made questionnaires were used. The questionnaires were designed in a way that it had 5 main components and 25 items based on the five-choice Likert Scale. The content and face validity of the questionnaires were confirmed by related experts and professors. In order to ensure the reliability the Cronbach's alpha was applied. The Coefficient showed high reliability of the questionnaires (it was 0.879 , based on a 30 person sample). The questionnaires were presented to the faculty members and from the total number of questionnaires, 133 persons answered to the questionnaires. Data analysis was done through descriptive and inferential statistic by SPSS-19 software. In descriptive statistic the frequency, percentage, mean, and standard deviation was calculated. In inferential statistic, for question number 1 to 5 one sample t-tests, for question 6 Friedman test, and for question 7 MANOVA were applied. In the analysis of question number 7 , where there was meaningful difference the LSD test was applied to find out which of two groups are different.

Table 1: the frequency and percentage of the questions

\begin{tabular}{|c|c|c|c|c|c|c|c|c|}
\hline 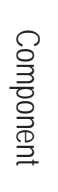 & $\stackrel{\overline{\mathbb{D}}}{\rightrightarrows}$ & 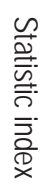 & 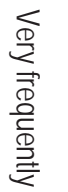 & $\begin{array}{l}\frac{T}{\mathbb{D}} \\
\frac{\mathbb{D}}{\mathbb{D}} \\
\stackrel{\mathbb{D}}{\rightleftharpoons}\end{array}$ & 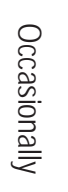 & 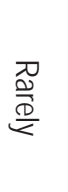 & $\underset{\mathbb{D}}{\underset{\mathbb{D}}{\mathbb{Z}}}$ & $\begin{array}{l}\underset{\mathbb{D}}{\mathbb{D}} \\
\stackrel{3}{5}\end{array}$ \\
\hline \multirow{13}{*}{ 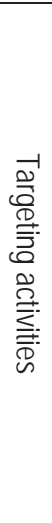 } & Limiting productivity with a productive approach & $\begin{array}{l}F \\
P\end{array}$ & $\begin{array}{c}29 \\
22.0\end{array}$ & $\begin{array}{c}65 \\
49.2\end{array}$ & $\begin{array}{c}21 \\
15.9\end{array}$ & $\begin{array}{l}12 \\
9.1\end{array}$ & $\begin{array}{c}5 \\
3.8\end{array}$ & 3.77 \\
\hline & \multirow[b]{2}{*}{ Limiting in-universities plans with a productive approach } & $\mathrm{F}$ & 21 & 48 & 43 & 18 & 2 & 3.52 \\
\hline & & $P$ & 15.9 & 36.4 & 32.6 & 13.6 & 1.5 & \\
\hline & \multirow{2}{*}{ Organizing cultural activities } & $\mathrm{F}$ & 51 & 56 & 23 & 2 & 0 & 4.18 \\
\hline & & $P$ & 38.6 & 42.4 & 17.4 & 1.5 & 0 & \\
\hline & \multirow{2}{*}{ Limiting or even stopping physical development } & $\mathrm{F}$ & 40 & 37 & 34 & 17 & 4 & 3.70 \\
\hline & & $P$ & 30.3 & 28.0 & 25.8 & 12.9 & 3.0 & \\
\hline & \multirow{2}{*}{ Deleting repetitions and parallel works with no added value } & $\mathrm{F}$ & 78 & 26 & 16 & 10 & 2 & 4.27 \\
\hline & & $P$ & 59.1 & 19.7 & 12.1 & 7.6 & 1.5 & \\
\hline & \multirow{2}{*}{ Deletion of unpopular courses } & $\mathrm{F}$ & 32 & 51 & 38 & 9 & 3 & 3.75 \\
\hline & & P & 24.1 & 38.3 & 28.6 & 6.8 & 2.3 & \\
\hline & \multirow{2}{*}{ Organizing physical facilities of universities } & $\mathrm{F}$ & 56 & 39 & 18 & 17 & 2 & 3.98 \\
\hline & & $P$ & 42.4 & 29.5 & 13.6 & 12.9 & 1.5 & \\
\hline \multirow{10}{*}{ 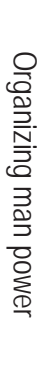 } & \multirow{2}{*}{ Transferring man power across branches } & $\mathrm{F}$ & 32 & 38 & 44 & 16 & 0 & 3.66 \\
\hline & & $P$ & 24.6 & 29.2 & 33.8 & 12.3 & 0 & \\
\hline & \multirow{2}{*}{ Holding practical in-service courses training for faculty members and employees } & $\mathrm{F}$ & 28 & 52 & 35 & 15 & 5 & 3.61 \\
\hline & & $P$ & 21.1 & 37.6 & 26.3 & 11.3 & 3.8 & \\
\hline & \multirow{2}{*}{ Specialitism in assigned affairs } & $F$ & 26 & 61 & 36 & 6 & 2 & 3.79 \\
\hline & & $P$ & 19.8 & 46.6 & 27.5 & 4.6 & 1.5 & \\
\hline & \multirow{2}{*}{ Early retirement plans } & $F$ & 22 & 55 & 46 & 8 & 2 & 3.65 \\
\hline & & $P$ & 16.5 & 41.4 & 34.6 & 6.0 & 1.5 & \\
\hline & \multirow{2}{*}{ Developing welfare facilities for the personals to increase efficiency } & $\mathrm{F}$ & 38 & 48 & 32 & 11 & 4 & 3.78 \\
\hline & & $\mathrm{P}$ & 27.0 & 36.4 & 24.2 & 8.3 & 3.0 & \\
\hline \multirow{8}{*}{ 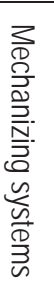 } & \multirow{2}{*}{ Reducing bureaucracy and facilitating office jobs } & $\mathrm{F}$ & 62 & 39 & 25 & 5 & 2 & 4.16 \\
\hline & & $P$ & 46.6 & 29.3 & 18.8 & 3.8 & 1.5 & \\
\hline & \multirow{2}{*}{ Using a comprehensive system in all branches } & $\mathrm{F}$ & 46 & 47 & 27 & 12 & 1 & 3.94 \\
\hline & & $P$ & 34.6 & 35.3 & 20.3 & 9.0 & 0.8 & \\
\hline & \multirow{2}{*}{ Mechanizing roll- call and evaluating students systems } & $\mathrm{F}$ & 42 & 41 & 31 & 11 & 7 & 3.78 \\
\hline & & $P$ & 31.8 & 31.1 & 23.5 & 8.3 & 5.3 & \\
\hline & \multirow{2}{*}{ Promoting virtual and electronic trainings } & $\mathrm{F}$ & 39 & 55 & 20 & 5 & 11 & 3.82 \\
\hline & & P & 30.0 & 42.3 & 15.4 & 3.8 & 8.5 & \\
\hline
\end{tabular}


Table 1: the frequency and percentage of the questions

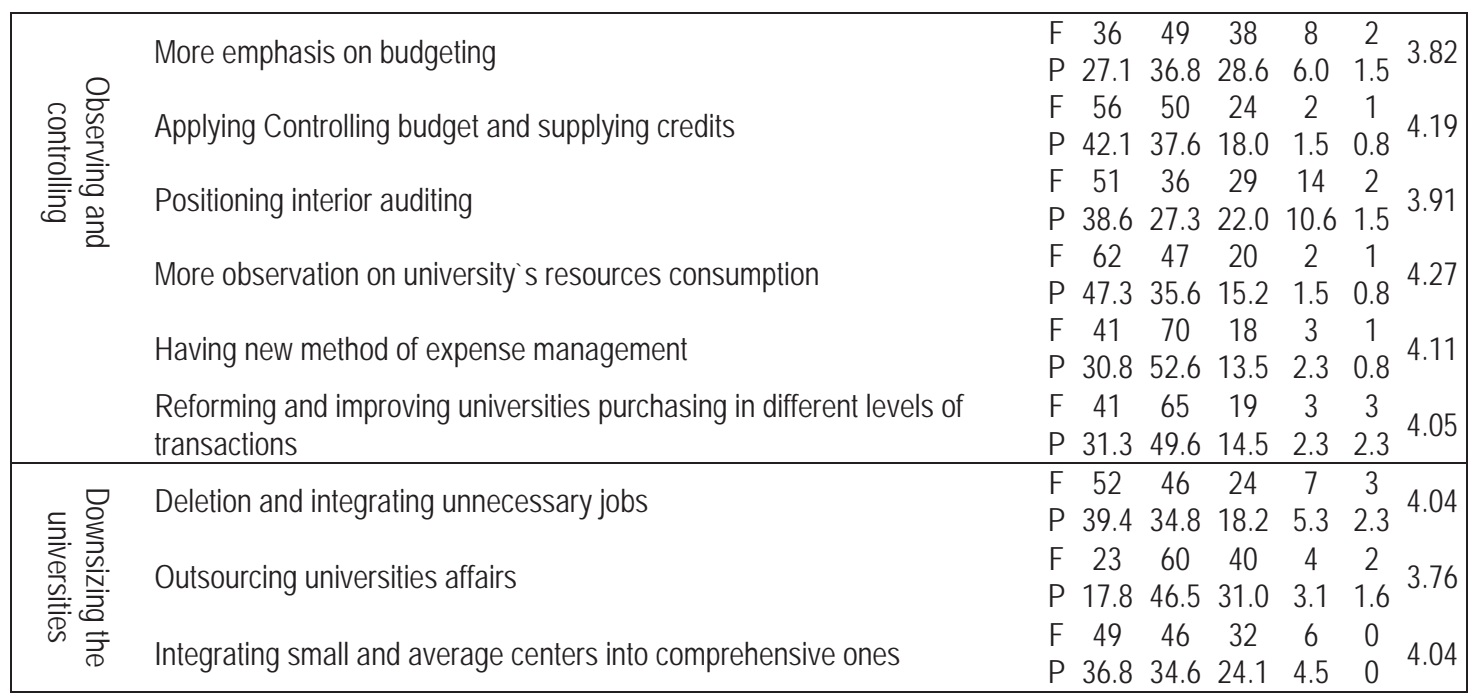

The investigation index shows that about 5 percent of the future stock returns is defined by the regression model. It shows that about 5 percent of the changes are depicted by the regression model.

\section{Inferential Findings of the Study}

In this section the research questions will be analyzed separately. It should be mentioned that since there were no similar research studies the comparison to other studies is not feasible.

\subsection{To what extent does the targeting of the Islamic Azad universities' activities influence the expenses reduction?}

Table 2: the comparison of the mean of the effect of targeting university`s activities on expense reduction with mean of 3

\begin{tabular}{|ccccccc|}
\hline Component & Mean & Standard Deviation & Mean of standard deviation & $\mathrm{T}$ & Degree of freedom Meaning level \\
\hline Targeting university`s activities & 3.88 & 0.49 & 0.04 & 20.63 & 132 & 0.000 \\
\hline
\end{tabular}

As it is shown in table 2, the mean of the effect of targeting universities activities is 3.88. on the other hand, calculated $t$ was bigger than the $t$ in the table and the meaning level is less than 0.05 therefore, it could be said surely that targeting Islamic Azad university activities has effect on the reducing expenses. As it is indicated in Table.1, although among the examined items in targeting university's activities " deleting repetitions and parallel works with no added value" have the highest mean, the mean of items in this component are higher than average level (3). Allocating highest mean to the "deleting repetitions and parallel works with no added value" by the faculty members might mean that in office jobs process, there are parallel activities and repetitions which waste universities resources and slow down the procedure of main activities (teaching and research activities) of universities and that could result in losing motivations, quality, and validity of the university. In this respect performing engineering method for recognizing and deleting activities without added value with the aim of facilitating performance needs policy makers' attentions. The findings proved that with systematizing cultural activities, organizing physical facilities of the university, limiting congresses and research programs in universities with increasing productivity approach, limiting or stopping physical development, and deleting unpopular courses we can prevent wasting university's resources and manage the expenses considerably. 


\subsection{How does organizing man power in Islamic Azad University has an effect on reducing expenses?}

Table 3: the comparison of the mean of the effect of organizing man power on expense reduction with mean of 3

\begin{tabular}{|ccccccc|}
\hline Component & Mean & Standard Deviation & Mean of standard deviation & $\mathrm{T}$ & Degree of freedom & Meaning level \\
\hline Organizing man power & 3.70 & 0.58 & 0.05 & 13.91 & 132 & 0.000 \\
\hline
\end{tabular}

As it is shown in Table 3, The mean of the effect of organizing man power on reducing expenses in Islamic Azad University is 3.70. on the other hand calculated $t$ is bigger than Table`s $t$ and the meaningful level is less than 0.05 so it could be said with 95 confidence that organizing man power in Islamic Azad university have effect on reducing expenses. As it is indicated in Table.1, although among the examined items in organizing man power the item " Specialitism in assigned affairs" have the highest mean, the mean of other examined items in this component is higher than average level( 3). Allocating highest mean to the "Specialitism in assigned affairs" might be due to the fact that in some sections, personals' activities are not related to their degree, education, and proficiency levels which result in lack of motivation, repetition, and doing activities with no added value and consequently waste the university resources. Sa adat (1997), suggested that considering employees' success circles and classifying them in man power program is very significant. The findings shows that by performing early retirement with increasing productivity approach, holding comprehensive and practical in-service training courses for faculty members, and transferring them across branches the expenses could be managed considerably.

\subsection{How does mechanizing office, financial, training, and research systems in Islamic Azad University have an effect on} reducing expenses?

Table 4: the comparison of the mean of the effect of mechanizing sytems on expense reduction with mean of 3

\begin{tabular}{|ccccccc|}
\hline Component & Mean & Standard Deviation & Mean of standard deviation & $\mathrm{t}$ & Degree of freedom & Meaning level \\
\hline $\begin{array}{c}\text { Mechanizing office, financial, } \\
\text { training, and research systems }\end{array}$ & 3.92 & 0.64 & 0.05 & 43.916 & 132 & 0.000 \\
\hline
\end{tabular}

As it is shown in Table 4, the mean of the effect of mechanizing office, financial, training, and research systems on reducing expenses in Islamic Azad University is 3.92. On the other hand, calculated $t$ is bigger than Table`s $t$ and the meaningful level is less than 0.05 so it could be said with 95 confidence that mechanizing office, financial, training, and research systems in Islamic Azad university have effect on reducing expenses. As it is indicated in Table.1, although among the examined items in mechanizing office, financial, training, and research systems the item " Reducing bureaucracy and facilitating office jobs" have the highest mean, the mean of other examined items in this component is higher than average level( 3). Allocating the highest mean to the "Reducing bureaucracy and facilitating office jobs" shows that due to repetitions and parallel activities, ambiguity in job process, probably using tastes from executives and having unnecessary rules, the office systems are slow and have bureaucracy. On the other hand equipping organizations to advanced technologies and applying integrated software and avoiding island software will reduce bureaucracy and facilitate office affairs as well as reducing universities expenses so that the university could increase competitive power. It should be mentioned that training employees for appropriate applying new technologies is an important issues. Although technology helps to down size the organization and economize the personal and office expenses, sometimes inappropriate use of these facilities not only do not help to reduce man power but also in some occasions the manpower increase because of the lack familiarity with new technology and resistance to changes.

\subsection{How does observation and controlling in Islamic Azad University have an effect on reducing the expenses?}

Table 5: the comparison of the mean of the effect of observation and controlling on expense reduction with mean of 3

\begin{tabular}{|ccccccc|}
\hline Component & Mean & Standard Deviation & Mean of standard deviation & $\mathrm{T}$ & Degree of freedom & Meaning level \\
\hline Observation and controlling & 4.06 & 0.55 & 0.05 & 22.01 & 132 & 0.000 \\
\hline
\end{tabular}

As it is shown in Table 5, the mean of the effect of observation and controlling on reducing expenses in Islamic Azad University is 4.06. On the other hand, calculated t is bigger than Table's $t$ and the meaningful level is less than 0.05 so it 
could be said with 95 confidence that observation and controlling in Islamic Azad university have effect on reducing expenses. As it is indicated in Table.1, although among the examined items in observation and controlling the item " more observation on university's resources consumption" have the highest mean, the mean of other examined items in this component is higher than average level (3). Allocating the highest mean to the " more observation on university's resources consumption" suggested that management of university financial resources is important so that one could claim that management of university financial resources is more important than reducing the expenses. Because when financial recourse is managed correctly unnecessary expenses would be prevented. The findings revealed that by having new methods of expenses management, having supplying credits and controlling budget systems, reforming and improving necessary services for university and purchasing procedures in different levels of transactions, more emphasis on budgeting, and positioning interior auditing the expenses could be manage greatly. It should be considered that auditing and budgeting are tools of controlling and having the tool is not the main issue but the way these tools are used and applied is important. As zahedani (2000) claimed, interior auditing is an investigating system for evaluating inorganizations activities for recognizing deviation from determined standard. The data obtain from this system should be in a way that inform managers about organizations procedures, observing governmental regulations, having appropriate financial position, profit making of actions, and coordination of different parts of the organization. And as Nabavi (1997) claimed after having interior controlling, the fastest and the most important step is deviations recognition through examining strategic points, analyzing the causes and having immediate reforming actions to achieve standards, and approved classifications. Ultimately observation and controlling is one the main components of managements in any organization so that without that other components of the management like planning, organizing, and leadership are imperfect.

\subsection{How does downsizing the Islamic Azad universities have an effect on reducing expenses?}

Table 6: the comparison of the mean of the effect of downsizing the university on expense reduction with mean of 3

\begin{tabular}{|ccccccc|}
\hline Component & Mean & Standard Deviation & Mean of standard deviation & $\mathrm{T}$ & Degree of freedom & Meaning level \\
\hline Downsizing the university & 3.95 & 0.64 & 0.05 & 17.07 & 132 & 0.000 \\
\hline
\end{tabular}

As it is shown in Table 6, the mean of the effect of downsizing the university on reducing expenses in Islamic Azad University is 3.95. On the other hand, calculated $t$ is bigger than Table's $t$ and the meaningful level is less than 0.05 so it could be said with 95 confidence that downsizing Islamic Azad university has effect on reducing expenses. As it is indicated in Table.1, although among the examined items in downsizing the university the item " deletion and integrating unnecessary jobs" have the highest mean, the mean of all other examined items in this component is higher than average level( 3). Allocating the highest mean to the "deletion and integrating unnecessary jobs " and "Integrating small and average centers into comprehensive ones" suggested that the size of an organization is one the main factors in reducing expenses. Since proportionate to the size of any organization manpower, facilities and equipment are required. The bigger an organization, the more requirement to the man power, equipment, buildings and different other things, then, the total expenses will increase. Therefore, the logical downsizing of university in a way that it doesn't damage the services is one the main factors in reducing expenses in universities. In present conditions in which most branches and small and average centers away from provinces are short of university students, integrating centers and small or average branches into big and comprehensive ones and deleting and integrating jobs and unnecessary sections would reduce university expenses. The facilities of these branches could be used for development and promotion of activities in other sections of universities or in comprehensive branches of universities. Furthermore, outsourcing universities affairs is another step which could be done for downsizing the universities.

\subsection{How is the ranking of these five components considering the effect of reducing expenses in Islamic Azad} universities?

In order to rank the effective components on reducing expenses in Islamic Azad university the Fredman`s test was applied. The results are shown in Table 7 and Table 8. 
Table 7: the mean of ranking of the effective components on reducing expenses in Islamic Azad University

\begin{tabular}{|cc|}
\hline Components & Ranking mean \\
\hline Targeting university`s activities & 3.08 \\
Organizing manpower & 3.62 \\
Mechanizing office, financial, training, and research systems & 2.93 \\
Observation and controlling & 2.48 \\
Downsizing the university & 2.89 \\
\hline
\end{tabular}

As it is shown in Table 7, by faculty members' perspectives, organizing manpower has the highest rank and observation and controlling has the lowest rank in the degree of the effect of reducing expenses. moreover, organizing manpower, targeting university`s activities, mechanizing office, financial, training, and research systems, downsizing the university, and observation and controlling are respectively effective on reducing expenses in Islamic Azad Universities.

Table 8: Fredman Test

\begin{tabular}{|cc|}
\hline Number & 133 \\
\hline Chi-square & 36.922 \\
Degree of freedom & 4 \\
Meaningful level & 0.000 \\
\hline
\end{tabular}

As it is shown in Table 8, since the meaningful level is less than 0.05 with 95 confidence we can claim that the findings from among total ranking of five factors reducing expenses in Islamic Azad University by faculty members perspective in sig less than 0.05 is meaningful ( the chi-square is 36.922 ). Observation and controlling has the lowest rank here. This could resulted from the fact that training and research activities which make the nature of faculty members 'occupations are very dynamic and is not limited to strict time and place`s regulations as a result extra observation and controlling cannot improve their performances, although faculty members do not ignore the laws, this may cause lack of motivation, lowering of quality and consequently result in validity of the university. Hence, it seems that the faculty members are laworiented and welcome logical and wise observation and controlling.

5.7 Are there any meaningful differences among participants 'perspectives on the effect of examined five factors on expenses reduction in Islamic Azad University based on demographic factors?

Table 9: multivariate analysis of variance (MANOVA) for effective factors on reducing expenses in Islamic Azad Universities based on demographic variables.( age and service record)

\begin{tabular}{|c|c|c|c|c|c|c|}
\hline Variable & Factors & Sum of Square & Degree of Freedom & Mean of Square & $\mathrm{F}$ & Meaningful Level \\
\hline \multirow{5}{*}{ Age } & Targeting university`s activities & 0.139 & 4 & 0.035 & 0.140 & 0.967 \\
\hline & Organizing manpower & 2.659 & 4 & 0.665 & 2.051 & 0.091 \\
\hline & $\begin{array}{l}\text { Mechanizing office, financial, } \\
\text { training, and research systems }\end{array}$ & 1.429 & 4 & 0.357 & 0.858 & 0.491 \\
\hline & Observation and controlling & 1.680 & 4 & 0.420 & 1.382 & 0.244 \\
\hline & Downsizing the university & 0.432 & 4 & 0.108 & 0.257 & 0.905 \\
\hline \multirow{5}{*}{$\begin{array}{l}\text { Service } \\
\text { Record }\end{array}$} & Targeting university`s activities & 0.799 & 3 & 0.266 & 1.077 & 0.361 \\
\hline & Organizing manpower & 1.602 & 3 & 0.534 & 1.598 & 0.193 \\
\hline & $\begin{array}{l}\text { Mechanizing office, financial, } \\
\text { training, and research systems }\end{array}$ & 2.746 & 3 & 0.915 & 2.281 & 0.083 \\
\hline & Observation and controlling & 0.346 & 3 & 0.915 & 0.369 & 0.776 \\
\hline & Downsizing the university & 1.227 & 3 & 0.409 & 0.981 & 0.404 \\
\hline
\end{tabular}

As it is shown in Table .9, there are no meaningful differences between the scores of effective factors on reducing expenses in Islamic Azad University by faculty members' perspectives based on age and service record. 


\section{Conclusion}

The findings revealed that by faculty members ' perspective the effect of five factors on reducing expenses in Islamic Azad University was more than the mean therefore; all five factors are effective ones for reducing expenses. Moreover, the results showed that in ranking of examined factors, organizing man power, targeting university's activities, mechanizing office, financial, training, and research systems, downsizing the university, and observation and controlling, are in the first to the fifth order respectively based on the degree of the effect on reducing expenses, and organizing man power had the highest and observation and controlling had the lowest rank. The results suggest that service records and ages of faculty members do not have a meaningful effect on their perspectives on the effect of examined factors for reducing the university expenses.

\section{References}

Beath, J., and Owen, R.F., and Poyago-Theotoky, J., and Ulph, D. (2003). Optimal Incentives for Income-Generation in Universities: the Rule of Thumb for the Compton Tax. International Journal of Industrial Organization. (PP. 1301-1322).

Horne, J., Hu, B. (2008). Estimation of Cost Efficiency of Australian Universities. Mathematics and Computers in Simulation 78. (PP. 266-275).

Johnstone, D. B. \& Marcucci, P. (2010). Financing higher education in international perspective: Who pays? Who should pay? Baltimore: The Johns Hopkins University Press.

OECD. (2007). Funding Systems and Higher Education Systems.

Odden, A. and William, C. (1998). School Finance Systems: Aging Sructure in Need of Renovation. Educational Evaluation and Policy Analysis, Vol. 20, No. 3.

Odden, A. (2004). Summery and Reflections on 14 Years of CORE School Finance Redesign Research. Madison, Consortium for Policy Research in Education, University of Wisconsin - Madison.

UNSCO/OECD.(2002). Financing Education - Investment and Return. Analysis of the World Education Indicators 2002 Edition Paris, UNSCO/OECD.

Vegas, E. (2002). School Choice, Student Performance and Teacher and School Characteristics: The Chilean Case; Washington, D.C. Development Research Group, World Bank.

Entezari, E. (2013).Choosing the appropriate mechanism for the allocation of the general resources to the higher education system. Quarterly journal of Research and Planning in Higher Education. Volume 19. Issue 2.

Arabi, M., and Dehqan, N. and Aqoli, F., (2012). Customs import of re-engineering processes, Journal of Management, Business Studies, 46 (11), (pp.73-63).

Asad Niya, H., Jafari, M., Heidari, M. (2013). Effect of Operational Audit efficiency for the implementation of police related development projects. Police Organizational Development Journal, 9, 43, (pp. 44-32).

Hussein Pour, M. (2012). An analysis of the research activity inhibiting Factors of the the professors of the humanities faculty. New findings in psychology, Vol. 6, Issue 19, (pp. 95-79).

Dullanshimon, Al, Shuler Rendal, S. (1995). Personnel and human resource management. Translated by: Toussi and Saebi. The center of public administration education

Zahedani, N. (1998). Investigating the role of internal audit for implementing the optimal monitoring. Unpublished M.A. thesis of the public administration. Islamic Azad University, Dehaqan Branch.

Saadat, A. (1994). Personnel's progress management. Management knowledge. Issue 27 and 28.

Safari, A., (2005).the important effective factors in increasing the financial resources. Students' applies and decrease of costs of the Islamic Azad university: from the view point of the managers. The unpublished M.A. thesis of financial management. Islamic Azad University, Isfahan (Khorasgan) branch.

Farajpahlou, A., Makizadeh, F. (2010). on the analysis of the efficiency costs of the data base of Yazd university in 2009. Journal of academic library and information studies. Volume 44. Issue 54.

Karami, M.(2012). The status of electronic customs in facilitating business. Journal of parliament and research. 66(18), (pp. 32-62).

Nabavi, A. (1995). Accounting principles. Tehran. Farvardin publications.

Nouhebrahim, A.R. (2002). Deficit and waste of cost in public administration at the level of higher education. Quarterly journal of Research and Planning in Higher Education, volume 26. 